\title{
Cytologic Manifestations of Vaginitis
}

\author{
Farheen $\mathbf{A}^{1}$, Humera $\mathbf{A}^{2}$ \\ ${ }^{1}$ Dr. Ayesha Farheen, Assistant Professor, Department of Pathology, ESIC Medical College, Gulbarga, ${ }^{2}$ Dr. Aisha \\ Humera, Assistant Professor, Department of OBG, KBNIMS, Gulbarga, Karnataka, India.
}

Address for Correspondence: Dr. Ayesha Farheen, E-mail id: drayesha_999@yahoo.co.in

\begin{abstract}
Introduction: As the lower genital tract is directly exposed to the external environment, it is subjected to inflammation as well as infection, which may remain localized or may progress to other areas such as the endometrium, fallopian tubes, peritoneal cavity and, less likely, the ovaries. Vaginitis is a common health problem. The main aim of the present study is to recognize the cytological manifestations in vaginitis and to identify the possible causative agent. Materials and Methods: Cytologic evaluations of vaginal smear were made in 167 patients. Clinical details were obtained by examining the patients and relevant investigations were noted. With the consent of the patient posterior vaginal fornix was swabbed with cotton tipped applicator. PH was determined. Whiff's amine test was done for presence of fishy amine odor. Wet mount preparation was immediately made and examined under microscope. Three smears were made, one each for Gram's, Giemsa and papanicolaou. Result: Out of 167 cases, most common cytological diagnoses offered were Bacterial vaginosis $(50.8 \%)$, Koilocytotic atypia (13.7\%), Trichomonas vaginalis infestations $(12.5 \%)$, and vaginal candidiasis (4.8\%). Majority were in age group 21-30 years (49.59\%). Conclusion: There were diverse cytologic manifestations in vaginitis and was useful in identifying the possible etiological factors. Hence the results obtained are useful in screening large population.
\end{abstract}

Keywords: Cytological evaluation, vaginitis, bacterial vaginosis

\section{Introduction}

As the lower genital tract is directly exposed to the external environment, it is subjected to inflammation as well as infection, which may remain localized or may progress to other areas such as the endometrium, fallopian tubes, peritoneal cavity and less likely, the ovaries [1]. Vaginitis and vaginosis refer to vaginal infection, skin diseases involving the vagina, or a disruption of the normal vaginal flora. Common and nonspecific symptoms include vaginal discharge, odor, introital itching, or irritation. Vaginosis refers to vaginal disease unassociated with inflammation as characterized by redness and a wet mount showing an increase in white blood cells. Vaginitis is associated with clinical and wet-mount changes of inflammation [2]. Vaginitis is a clinical syndrome characterized by vaginal discharge, vulvar irritation, or malodorous discharge [3]. These patients complain of an excessive vaginal discharge, which may be white (leucorrhea), discolored or blood stained. This may not be always due

Manuscript received: $1^{\text {st }}$ February 2017

Reviewed: $8^{\text {th }}$ February 2017

Author Corrected: $16^{\text {th }}$ February 2017

Accepted for Publication: $23^{\text {rd }}$ February 2017 to infection, since hormonal changes and allergies may be associated with similar manifestations [4]. Vaginitis is a common health problem [5]. The normal flora of the vagina varies from person to person but lactobacilli are usually the preponderant organism. Bacterial flora also contains other aerobic and anaerobic microorganisms. Some of these are considered to be pathogenic. Many of these organisms can be identified in cytologic preparation [6].

It is recognized that, bacterial vaginosis may be associated with pelvic inflammatory disease, preterm premature rupture of the membranes (PROM), post operative gynecologic infections and abnormal Papanicolaou smear [7].

Vaginal infections lead to inflammatory changes in the epithelial cells which may be cytoplasmic abnormalities of diagnostic importance. Symptoms of vaginitis are non-specific and neither self diagnostic nor diagnosis by a physician is reliable without laboratory confirmation [8]. 


\section{Materials and Methods}

Study of 'Cytologic Manifestations of Vaginitis' was conducted in the pathology department, KBNIMS, Gulbarga, over a period of two years from $1^{\text {st }}$ July 2013 to $30^{\text {th }}$ June 2015 . This study consists of 167 patients referred for cytological evaluation to the pathology department.

Inclusion crite ria: All the patients, clinically having the symptoms of vaginitis, were included in the study.

Exclusion criteria: Patients in menstrual period and patients who had taken antibiotics or received any treatment for vaginitis with in the previous month were excluded from this study.
With the prior consent, patient was subjected to detail clinical examination. Posterior fornix was swabbed with a cotton tipped applicator. $\mathrm{pH}$ was determined by using $\mathrm{pH}$ strips. Whiff's amine test was done as follows, the swab was mixed with two drops of 10 percent potassium hydroxide on a glass slide. This solution was immediately examined for the presence of fishy amine odour. Wet mount preparation was immediately made and examined under microscope. A second sample was obtained with another swab and three smears were made, one each for Gram's Stain, Giemsa Stain and Papanicolaou Stain. All the smears were carefully examined for the various cytologic manifestations and the causative agent. Data obtained has been analyzed.

\section{Results}

A prospective study on cytologic manifestations of vaginitis on 167 patients in the department of Pathology KBNIMS, Gulbarga, Salient features observed in this study were as follows.

Age: Age of the patients ranged from 19 years to 70 years and the majority of the Patients were in the age group of 21 30 years $(49.59 \%)$

Table-1: Age distribution in Vaginitis.

\begin{tabular}{|c|c|c|c|}
\hline Sl. No. & Age (years) & Number of cases & Percentage of cases \\
\hline 1 & $15-21$ & 2 & 1.20 \\
\hline 2 & $21-30$ & 79 & 49.59 \\
\hline 3 & $31-40$ & 48 & 29.92 \\
\hline 4 & $41-50$ & 17 & 9.24 \\
\hline 5 & $51-60$ & 15 & 1.81 \\
\hline 6 & $61-70$ & 3 & $\mathbf{1 0 0}$ \\
\hline
\end{tabular}

Table-2: Clinical manifestations of Vaginitis

\begin{tabular}{|c|c|c|c|}
\hline Sl. No & Symptoms & Number of cases & Percentage of cases \\
\hline 1 & Homogenous grey white discharge & 117 & 70.05 \\
\hline 2 & Thick white discharge & 35 & 20.9 \\
\hline 3 & Discharge mixed with blood & 15 & 8.9 \\
\hline 4 & Greenish yellow discharge & 01 & 0.6 \\
\hline 5 & Mucopurulent discharge & 68 & 40.7 \\
\hline 6 & Foul smelling discharge & 67 & 40.1 \\
\hline 7 & Vaginal irritation / itching & 59 & 35.3 \\
\hline 8 & Burning micturition & 50 & 29.9 \\
\hline 9 & Low backache & 59 & 35.3 \\
\hline 10 & Menstrual disturbances & 42 & 25.1 \\
\hline 11 & Pain abdomen & 10 & 5.9 \\
\hline 12 & Dyspareunia & & \\
\hline
\end{tabular}


Clinical manifestations: The commonest clinical symptoms associated with vaginitis was history of Homogenous grey white discharge (117 cases). Other clinical manifestations were thick white discharge, discharge mixed with blood, greenish yellow discharge, mucopurulent discharge; itching (67 cases); burning micturition (59 cases), low backache (50 cases), pain abdomen (42 cases); menstrual disturbances (20 cases); dysparunia (10 cases), as mentioned in Table 2.

Cytological diagnoses: Cytological diagnoses observed in this study were bacterial infections (bacterial vaginosis, Gonorrheoa, Donovanosis, Actinomycoses and leptothrix vaginalis); viral infections (koilocytotic atypia); Fungal infections (candidiasis); Parasitic infestations (Trichomonas vaginalis infestation); Radiation induced vaginitis and senile vaginitis as.

Table-3: Cytological diagnosis of Vaginitis.

\begin{tabular}{|c|c|c|c|}
\hline S. No. & Cytological diagnoses & No. of cases & Percentage of cases \\
\hline 1 & Bacterial vaginosis & 85 & 50.8 \\
\hline 2 & koilocytotic atypia & 23 & 13.7 \\
\hline 3 & Trichomonas vaginalis infestation & 21 & 11.9 \\
\hline 4 & senile vaginitis & 08 & 4.8 \\
\hline 5 & candidiasis & 04 & 2.3 \\
\hline 6 & leptotjrix vaginalis & 03 & 1.8 \\
\hline 7 & Actinomyces infection & 01 & 0.6 \\
\hline 8 & Gonorrheae & 01 & 0.6 \\
\hline 9 & Radiation induced vaginitis & 01 & 0.6 \\
\hline 10 & Donovanosis & 20 & \\
\hline
\end{tabular}

In the present study maximum patients were in the age group of 21-30 years. The most common diagnosis was bacterial vaginoses $(50.8 \%)$. Many of these patients had thin homogenous grey white discharge, $\mathrm{pH}$ of discharge was more than 4.5, positive Whiff's amine test and presence of Clue cells on microscopy. Koilocytes, Dyskeratotic cells, Binucleation and multinucleation were observed in pap smear of HPV infected woman.. Wet mount for motile trichomonas organism was positive in all cases. Epithelial cells changes showed marked cytoplasmic eosinophilia with perinuclear halo, Cytoplasmic vacuolation and enlarged, hyperchromatic nucleus. Trichomonas vaginalis organisms, pear shaped with pale grey green cytoplasm and eccentrically located round vesicular nucleus was identified along with Profound inflammatory exudates consisting predominantly of neutrophil, agglomeration of neutrophil around the parasite resulting in "BB shot effect was also evident. Gram"s stained smear form gonococcal vaginitis showed characteristic Gram-negative intracellular diplococcic. Smear from Donovanosis showed macrophages with multiple vacuole containing straight or curved dumbbell shaped rods resembling "closed safety pins". Actinomyces was identified exclusively in patients wearing an intrauterine device.

\section{Discussion}

Vaginitis, although frequently due to infection, may also have non infectious causes. Moreover, mixed infections are not uncommon. The management of vaginitis remains largely empirical [8]. Cytologic manifestations are of diagnostic importance.

Vaginitis is one of the frequent clinical situations where cytological examination is requested. Kent also observed that vaginitis was the most common reason for a patient to visit her obstetrician-gynaecologist and vaginal discharge was the commonest symptom [9]. Majority belonged to the age group 21-30 years (49.59\%). Similar peak age incidence is noted in other studies [10]. Clue cells are quite specific in papanicolaou-stained smears, as well as in Gram stained smears, for detecting shift in flora from lactobacillus predominant to the anaerobic, Gardnerella Vaginalis population likely to be associated with bacterial vaginosis [11]. Koilocytes are pathognomic of a permissive HPV infection. Koilocytes are seen predominantly in LGSIL with features of HPV infection. Herrero et al (2000), have also found different age pattern of HPV prevalence, according to them this intriguing could be partly explained by cohort effect associated with changes in the sexual behavior [12]. 


\section{Research Article}

The diagnostic sensitivity of the vaginal smear for candida depends on the thoroughness of the individual who examines the slide, the variability of the fungal staining reaction and the quality of fixation. Sonnex and Collegue (1999) detected candida organisms in $78 \%$ of culture positive sample. Wet mount preparation, although quick and unexpensive, the test has limited sensitivity, ranging from 60-70\% [13]. Diagnosis of trichomoniasis was made by observing the organism in a stained smear. Demirezen and colleague (2000) observed in 16 out of 20 patients with T.vaginalis infestation that group of trichomonads surrounding the vaginal epithelial cells [14].

Gupta et al(1976) first reported the identification of actinomycosis in Papanicolaou smears from 13 women who had worn IUD for varying length. Accuracy of identification using light microscopy and pap stained material ranged from $48.5 \%$ to $8269 \%$. Development of PID in actinomycetes has been observed in many studies [15].

The microscopic diagnosis of gonococci is based on the cell morphology and arrangement, location, and colour of the bacteria. Gonococci are mainly identified as Gram- negative coffee bean-shaped diplococci, with concave sides opposing each other. Microscopy is a rapid point of care test that can be performed at bedside and facilitates the treatment of N.gonorrhoeae infection in patients at the first clinical visit [16]. Cannefax (1948) gave a full description of the organism. Donovan bodies are identified as mature or immature organisms that are present inside the cytoplasm of mononuclear cells [17]. Richens (1991), the finding of Donovan bodies provides a simple, highly specific way of confirming the diagnosis [18].

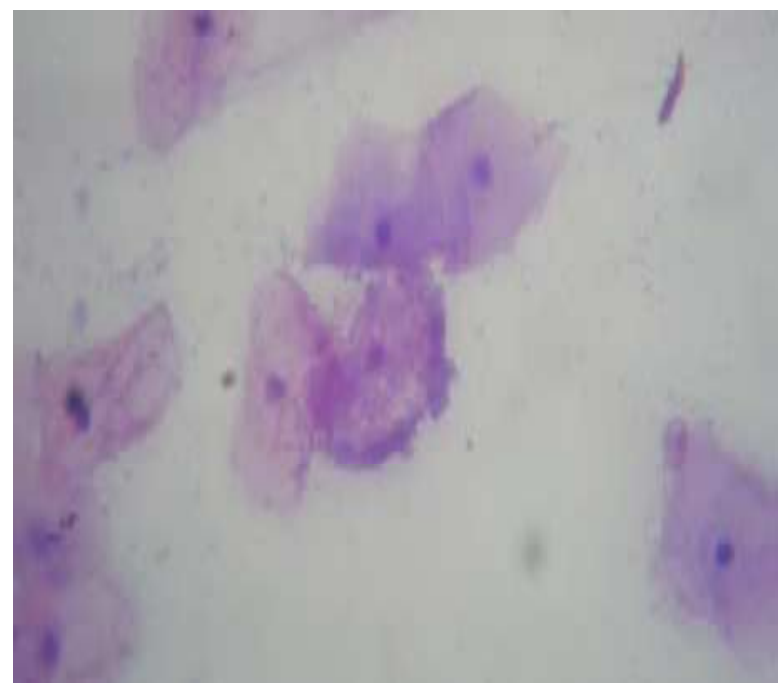

Fig.-1: Vaginal smear in bacterial vaginosis showing clue cells. Giemsa $x 400$

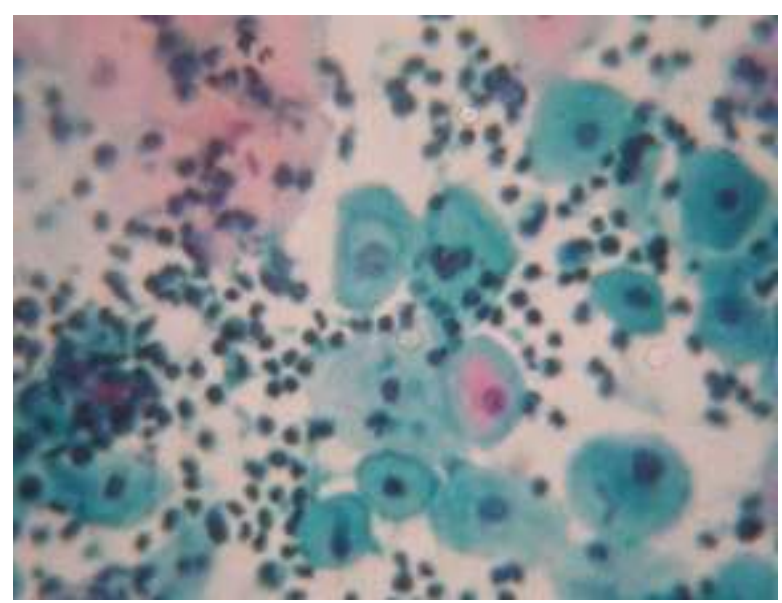

Fig.-3: Vaginal smear showing koilocytes Pap x 400

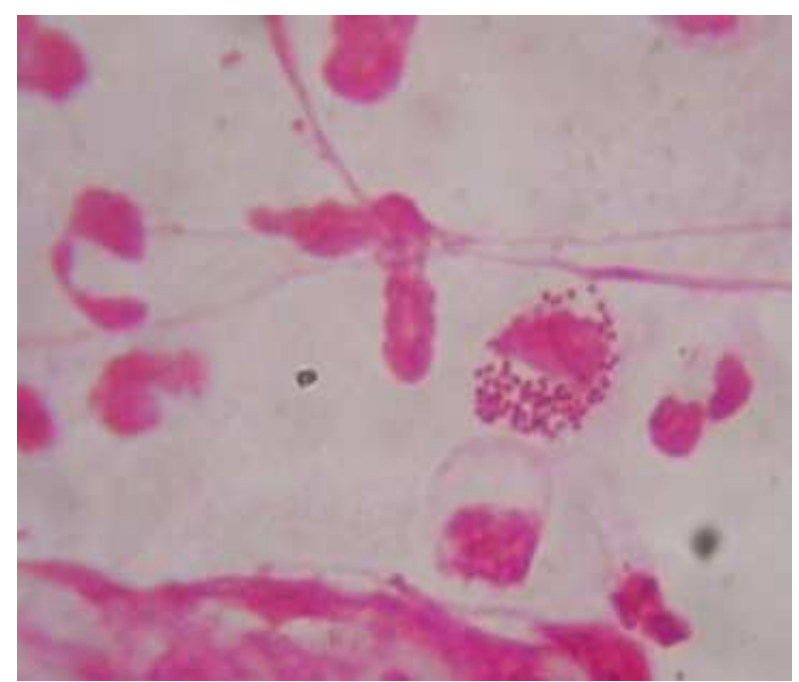

Fig.-2: Vaginal smear in Gonococcal Vaginitis showing Gram negative intracellular diplococcic Grams stain x 1000

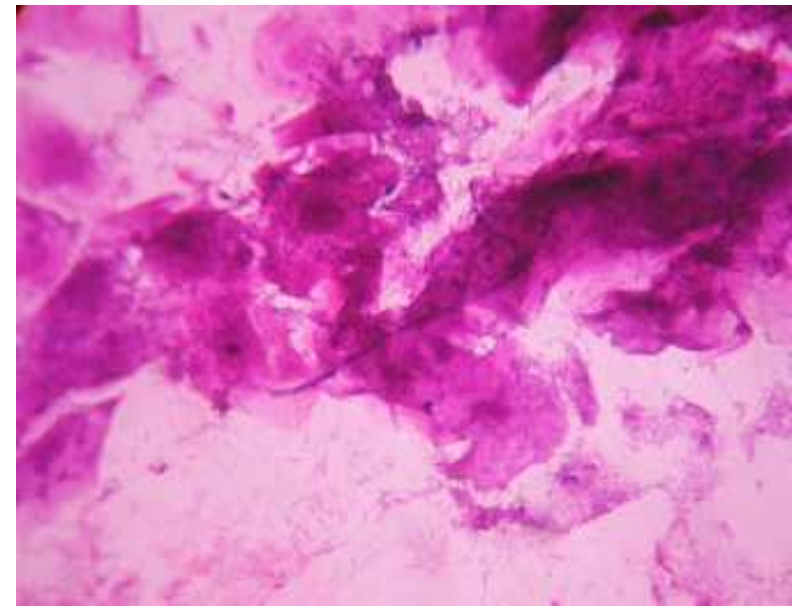

Fig.-4: Vaginal smear in vaginal candidiasis showing pseudohyphae Gram's x 400 


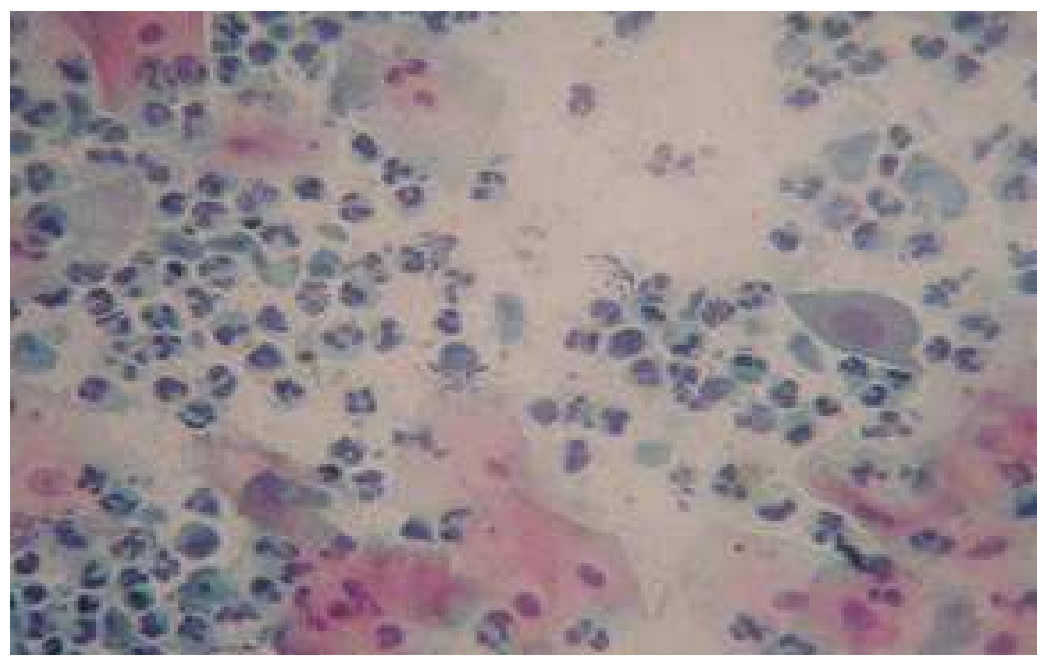

Fig.-5: Vaginal smear showing pear shaped trichomonas vaginalis organism in the background of inflammatory cells. Pap $x 400$

\section{Conclusion}

This study emphasizes the urgent need to study both normal vaginal flora and its physiologic variation together with the need to obtain the data on the role of vaginal flora in various forms of infections and noninfectious vaginitis as pathogenesis may remain obscure.

Funding: Nil, Conflict of interest: None initiated, Permission from IRB: Yes

\section{References}

1. Nuovo GJ. Microorganisms of cervix and vagina. In: Cytopathology of the lower female genital tract : An integrated approach.Philadelphia:Williams and Wilkins; 1994:341-75.

2. Edwards L. Vaginitis. In : Black M, Rudolph CMA, Edward L, Lynch PJ. Obstetric and gynaecological dermatology. 3rd edn. Mosby: Elsevier; 2008:301-16.

3. Ainbinder SW, Ramin SM, DeCherney AH. Sexually transmitted diseases and pelvic infections. In: DeCherney AH, Nathan L, Goodwin TM, Laufer Neri. Current Diagnosis and treatment Obstetric and Gynecology. 10th edn. McGraw Hill: New York, 2003; 662-95.

4. Boon ME, Gray W. Normal Vulva, vagina and cervix: hormonal and inflammatory conditions. In: Gray W, McKee GT, editors. Diagnostic cytopathology. 2nd ed. Philadelphia : Churchill Livingstone: 2003: 651-705.
5. Amsel R, Totten PA, Spiegel CA, Chen KC, Eschenbach D, Holmes KK. Nonspecific vaginitis. Diagnostic criteria and microbial and epidemiologic associations. Am J Med. 1983 Jan; 74 (1): 14-22.

6. Koss LG, Melamed MR editors. Benign disorders of uterine cervix and vagina. In: Koss' diagnostic cytology and its histopathologic basees. 5th ed. Vol.1, Philadelphia: Lippincott Williams and Wilkins; 2006: 241-81.

7. Henry MR. The Bethesda system 2001: an update of new terminology for gynaecologic cytology. Clinics in laboratory medicine 2003 Sep;23(3):585-603.

8. Sobel IO. Vaginitis. N Engl J Med 1997;337(26): 1896-1903.

9. David C, Foster. Vulvitis and Vaginitis. Current Opinion in Obstet \& gynecol 1993,5:726-32.

10. Kiviat NB, Paavonen JA, Brockway J, Critchlow $\mathrm{CW}$, Brunham RC, Stevens CE, Stamm WE et al. Cytologic manifestations of cervical and vaginal infections I. Epithelial and inflammatory cellular changes. JAMA 1985;253(7):989-96.

11. Schnadig VS, Davie KD, Shafer SK, Yandell RB, Islam MZ, Hannigan EV.The cytologist and bacterioses of the Vaginal - ectocervical area clues, commas and confusion. Acta Cytol 1989;33(3):287-97. 
12. Herrero R, Munoz N, et al. HPV International Prevalence Surveys in general population. (Abstract) 18 International HPV Conference. Barcelona. 2000: 126.

13. Sonnex C, Lefor W. Microscopic features of vaginal candidiasis and their relation to symptomalotogy Sex Transm Inf 1999;75:417-9.

14. Schwebke JR, Burgess D. Trichomonas. Clin Microbial Rev. 2004:17(4):794-802.

15. Demirezen S, Safi Z, Beksac S. The interaction of trichomonas vaginatis with epithelial cells, polymorphonuclear leucocytes and erythrocytes on vaginal smears; light microscopin observation. Cytopathol 2000;11:326-333.

16. Bhagawan BS, Gupta PK. Genital actinomycosis and intrauterine contraceptive devices - cytopathologic diagnosis and clinical significance. Hum Pathol 1978; 9 (5): 567-78.

17. Panikabutra K. Clinical aspects of uncomplicated gonorrheae in the female. Br J Vener Dis 1973;49(2): 213-15.

18. Richens j.The diagnosis and treatment of donovanosis (granuloma inguinale). Genitourin Med 1991;67:441-452.

\section{How to cite this article?}

Farheen A, Humera A. Cytologic Manifestations of Vaginitis. Trop J Path Micro 2017;3(1):20-25.doi: 10.17511/jopm.2017.i1.04. 